\title{
Kernos
}

Revue internationale et pluridisciplinaire de religion grecque antique

33 | 2020

Varia

\section{Dei e piante nell' antica Grecia}

\section{Hélène Collard}

\section{(2) OpenEdition \\ Journals}

Édition électronique

URL : https://journals.openedition.org/kernos/3506

DOI : $10.4000 /$ kernos.3506

ISSN : 2034-7871

\section{Éditeur}

Centre international d'étude de la religion grecque antique

\section{Édition imprimée}

Date de publication : 31 décembre 2020

Pagination : $342-344$

ISBN : 978-2-87562-264-8

ISSN : 0776-3824

\section{Référence électronique}

Hélène Collard, « Dei e piante nell' antica Grecia », Kernos [En ligne], 33 | 2020, mis en ligne le 31 décembre 2020, consulté le 04 décembre 2022. URL : http://journals.openedition.org/kernos/3506 ; DOI : https://doi.org/10.4000/kernos.3506

Ce document a été généré automatiquement le 4 décembre 2022

Tous droits réservés 


\title{
Dei e piante nell' antica Grecia
}

\author{
Hélène Collard
}

\section{RÉFÉRENCE}

Giampiera ARRIGONI (dir.), Dei e piante nell' antica Grecia I. Riflessioni metodologiche, Efesto, Demetra in Grecia, Magna Grecia e Sicilia, Kore Persefone, Ecate, Apollo, Afrodite, Bergamo, Sestante edizioni, 2018. 1 vol. 21,2 × 29,8 cm, 397 p. (Series Antiqua, 6). ISBN :

978-88-6642-284-6.

1 Cet ouvrage collectif est issu des travaux menés par les membres d'un groupe de recherche créé par Giampiera Arrigoni au sein de l'Université d'État de Milan: le «Gruppo delle piante ». Depuis sa création en 2011, ce groupe, composé de chercheurs venant d'horizons variés (historiens et historiens des religions, archéologues, philologues, philosophes...), s'est réuni de façon régulière mais informelle pour échanger autour de la thématique - très large - des dieux et des plantes.

2 Le résultat est une compilation de neuf articles très inégaux, tant en terme de quantité (plus de 100 pages pour l'article le plus long, une dizaine pour l'article le plus court) que de qualité et de contenu. Ces disparités peuvent certes s'expliquer par l'abondance (ou au contraire la rareté) des sources disponibles selon les contextes et les divinités étudiées. Ainsi, Déméter et Perséphone occupent une place prépondérante au sein du volume en raison de la profusion de matériel à disposition (voir p. 21), à l'inverse d'Hécate ou d'Héphaïstos, par exemple. Compte tenu précisément de ces écarts dans les données, n'aurait-il pas mieux valu organiser la matière différemment, autour d'une problématique précise, afin de donner plus d'homogénéité à l'ensemble ? C'est en effet le reproche majeur que l'on peut faire à cette publication: plus qu'une véritable entreprise collective menée autour d'une problématique bien définie, il s'agit en fait d'une juxtaposition d'études, sans lien réel entre elles au-delà d'une large thématique commune.

3 Le volume s'ouvre sur une brève préface, suivie d'une première contribution rédigée par l'éditrice, qui tient en quelque sorte lieu d'introduction : elle y dresse un état de la 
question (du « culte de l'arbre » à la place des plantes dans la mythologie et en contexte funéraire) et apporte quelques précautions méthodologiques. Mais il manque à cet ouvrage une introduction qui en préciserait les objectifs et les axes de recherche, qui identifierait les questionnements communs aux différents contributeurs, qui retracerait le chemin parcouru au sein du groupe de recherche et présenterait les différents articles. Ces précisions auraient sans doute permis au lecteur de mieux comprendre et situer la démarche, et donc de mieux appréhender les études présentées.

4 Les huit autres papiers portent tous sur une divinité précise, Déméter étant au centre de trois d'entre eux. Dans son article, Anna Però traite des plantes liées à Héphaïstos, tant dans les sources littéraires que dans les sources iconographiques et archéologiques. Son interprétation concernant l'association entre le dieu et le pin (une essence qui brûle particulièrement vite) est intéressante : elle y voit un lien avec le feu d'Héphaïstos, à la fois destructeur et civilisateur. En revanche, les arguments qui portent sur la peinture de vases et la couronne de lierre qu'y porte parfois le dieu semblent moins convaincants.

5 Viennent ensuite les trois études sur Déméter, chacune traitant d'un contexte géographique particulier. La première (G. Arrigoni), qui est de loin la plus abondante (109 p.), s'attache à la Grèce propre. Elle est divisée en 14 parties, toutes consacrées à une plante différente: l'auteure y recense les différentes attestations (présence ou utilisation) de végétaux en lien avec Déméter, que ce soit dans un sanctuaire ou un lieu précis ou lors d'une fête ou d'un rite déterminés, et ce, en croisant les différents types de sources. Elle offre ainsi un riche outil de travail pour d'éventuelles recherches ultérieures. La deuxième étude (M. Castoldi) liste quant à elle les témoignages archéologiques en provenance de Grande Grèce (offrandes votives et terres cuites en forme de feuilles ou de plantes, mais aussi traces d'offrandes végétales ou céréalières dans les sanctuaires), pour s'attacher ensuite aux représentations céramiques d'Apulie. Enfin, la troisième (A. Pace) est consacrée au culte de Déméter en Sicile et au rapport particulier qu'entretient la déesse avec le monde végétal, plus spécialement les céréales.

6 Le long article de L. Fabbri est un peu le pendant des trois précédents, puisqu'il concerne les plantes de Koré-Perséphone en Grèce, Grande Grèce et Sicile. Le narcisse, la jacinthe, le crocus, la grenade, le peuplier, le saule...: tout comme sa mère, Perséphone est liée à toute une panoplie de fleurs et de plantes variées. Son rapport au monde végétal ne se résume donc pas aux céréales, auxquelles on pense le plus souvent.

7 Les deux articles suivants sont plus courts. Celui de G.P. Foti porte sur la figure d'Hécate, d'une part dans les sources textuelles (principalement les Argonautiques), où elle entretient un rapport particulier avec les plantes "magiques ", d'autre part dans les sources iconographiques, où l'on voit se dessiner une « autre » Hécate, plus proche de déesses telles que Déméter ou Isis. M. Castoldi s'intéresse pour sa part à Apollon, cette fois uniquement aux travers des sources iconographiques - principalement la peinture sur vases - et archéologiques. Sans surprise, l'auteure traite surtout du laurier et du palmier, arbres incontestablement liés de façon privilégiée à Apollon. Mais l'explication dualiste qu'elle donne de leur présence dans l'iconographie - le palmier renvoyant à Délos, le laurier à Delphes - est quelque peu simpliste. Il y avait sans doute plus à dire sur ces questions et sur le choix même de ces deux essences. 
8 Enfin, le volume se clôt sur la contribution de C. Lambrugo, qui se penche sur le cas d'Aphrodite au moyen de trois dossiers judicieusement choisis : Aphrodite et les fleurs, Aphrodite à Lesbos et Aphrodite à Sicyone. Cette étude est certainement la plus intéressante et la plus fouillée : l'auteure ne se contente pas de lister les différents végétaux attestés en lien avec la déesse, mais tente de comprendre ces associations à la lumière des attributions qui sont celles d'Aphrodite dans le monde grec et qui constituent sa dynamis divine. Ainsi les fleurs, et notamment la rose, qui accompagnent la déesse de façon récurrente, tant dans les représentations figurées que poétiques et littéraires, renverraient tout particulièrement à l'univers de la kosmēsis, du parfum et de la séduction, un monde cher à celle que l'on surnomme "l'Aphrodite d'or ». Ce dernier article prouve donc que le sujet est riche et qu'il y a certainement matière à poursuivre l'entreprise inaugurée à Milan, en approfondissant quelque peu les pistes de recherche.

\section{AUTEURS}

HÉLÈNE COLLARD

Université de Liège 